\title{
Cultivating Olympic champions: A trampoline development environment from grass roots to podium
}

\author{
Michelle Seanor, Robert J. Schinke, Natalia B. Stambulova, Dave Ross \& \\ Georges Kpazai
}

To cite this article: Michelle Seanor, Robert J. Schinke, Natalia B. Stambulova, Dave Ross \& Georges Kpazai (2017) Cultivating Olympic champions: A trampoline development environment from grass roots to podium, Journal of Sport Psychology in Action, 8:2, 96-108, DOI: 10.1080/21520704.2017.1327908

To link to this article: http://dx.doi.org/10.1080/21520704.2017.1327908

\section{曲 Published online: 28 Jun 2017.}

Submit your article to this journal $₫$

Џ Article views: 61

Q View related articles $๘$

View Crossmark data $\nearrow$

Citing articles: 1 View citing articles 


\title{
Cultivating Olympic champions: A trampoline development environment from grass roots to podium
}

\author{
Michelle Seanor ${ }^{\mathrm{a}}$, Robert J. Schinke ${ }^{\mathrm{a}}$, Natalia B. Stambulova $\oplus^{\mathrm{b}}$, Dave Ross ${ }^{\mathrm{c}}$, \\ and Georges Kpazai ${ }^{\mathrm{a}}$ \\ a Laurentian University, Sudbury, Ontario, Canada; ${ }^{\mathrm{b}}$ Halmstad University, Halmstad, Sweden; ${ }^{\mathrm{C}}$ Skyriders \\ Trampoline Place, Richmond Hill, Ontario, Canada
}

\begin{abstract}
Olympic athletes' training environments influence their abilities to develop and excel as Olympians. Our authors considered a Canadian trampoline training environment with a history of developing Olympic medal-winning athletes from the grassroots through to Olympic podium. The sport environment is presented, drawing upon guided walks, through a cursory description in accordance with the Environmental Success Factors model derived from a holistic ecological approach to talent development. This presentation of the Skyriders Training Environment (STE) reveals how environmental factors facilitate Olympic talent development culminating in the highest level of artistic sport performance.
\end{abstract}

\section{KEYWORDS}

Athlete talent development environment; Olympic athletes; talent development; trampoline

Athletic careers can, in part, be understood by examining the transitions that mark changes in athletes' training environments. Bloom (1985) identified three general stages of development, taking into account the retrospective experiences of elite performers across domains. Focusing exclusively on what was found in relation to athletes; these stages were the early, middle, and late years, each differentiated by a change in coaching environments. During the early years, coaches made their sport fun, so as to "hook" the athletes into commitment. Then in the middle years, coaches focused on technical skill development. The late years were focused on teaching the athletes tactical and mental skills specific to elite performance and competition. Similarly, Stambulova (1994) described elite athletes' careers, with the focus placed on working through transitions that presented potential crisis points. These stages included the beginning of sport specialization, the transition to more intensive training in the chosen sport, from junior to senior/high achievement sport, amateur to professional sports, peak to the final stage, and the transition to the post-career. Researchers have also identified meta-transitions specific to Olympic level performances. Schinke, Stambulova, Trepanier, and Oghene (2015) identified that Canadian boxers transition through entering the Own the Podium program,

CONTACT Robert J. Schinke rschinke@laurentian.ca $\mathrm{B}$ School of Human Kinetics, Laurentian University, B-241 Ben Avery Building, 935 Ramsey Lake Road, Sudbury, ON, P3E 2C6, Canada. 
entering major international tournaments, Olympic qualification, focused preparation for the Olympic Games, to the Olympic podium (participation in the Games) and to the post-Games, as they prepared for their Olympic tournament. What these frameworks share is that they reveal the specific needs of aspiring athletes taking into account a holistic developmental perspective (Wylleman, Reints, \& De Knop, 2013). Moreover, all reveal that athletes require careful nurturing from their entry into sport, through the various crises and progressions they encounter on route to elite sport success.

The context surrounding athletes has a bearing on how these individuals develop from their earliest career stages to Olympic status. According to Bronfenbrenner (1994) “...in order to understand human development, one must consider the entire ecological system in which growth occurs" (p. 1). The same is true for athletes; the context surrounding athletes at each stage of their development has an influence on their potential to become successful elite performers. Researchers have considered environmental components that help shape athlete's developmental contexts during their careers stages, including the role of coaches (Bloom, 1985; Côté, Salmela, Trudel, Baria, \& Russell, 1995; Girginov \& Sandanski, 2004), the relationship between coaches and athletes (Orlick \& Partington, 1988; Schinke et al., 2008; Yang et al., 2016), and the influence of teammates (Bloom, 1985; Brown, 1985; Bruner, Munroe-Chandler, \& Spink, 2008; Morgan \& Giacobbi, 2006). Coaches are responsible for organizing athletes' training environments including such technical aspects as planning training sessions (Côté \& Salmela, 1996), contributing to the training atmosphere (Bloom, 1985), and facilitating successful working relationships (Schinke et al., 2008; Yang et al., 2015). Teammates provide modeling for athletes to encourage appropriate behaviors conducive of elite performance (DurandBush \& Salmela, 2002), whilst supporting them during transitions at critical points, such as the transition from a junior to a senior level competitor (Bruner et al., 2008; Morris, Tod, \& Oliver, 2016).

Martindale, Collins and Daubney (2005) took a first step to synthesizing contextual influences in athlete talent development by providing coaches with overarching recommendations to create successful athlete talent development environments. Henriksen and colleagues (see Henriksen, Stambulova, \& Roessler, 2010a, 2010b, 2011) proposed a holistic ecological approach to talent development and shifted attention from individual athletes to their broader developmental context or environment. Within the holistic ecological approach, athlete talent is considered as a set of competencies and skills that are the result of innate characteristics and learned behaviors nurtured via appropriate developmental environments.

\section{The Environmental Success Factors (ESF) model}

The ESF model (see Henriksen et al., 2010a) is an explanatory model derived from the holistic ecological approach to athlete talent development environments. The ESF model is designed to explain how contextual inputs in a sport environment, 
defined by preconditions and processes, interact to generate outputs from the environment in the form of the sport environment's organizational culture, individual and team achievements (including psycho-social competencies, such as autonomy and resilience, and athletic skills), and ultimately the overall success of the sport environment. The organizational culture is central to the model and is comprised of three levels: cultural artifacts, espoused values, and basic assumptions (Schein, 1992). The ESF model has been used to explain successful environments in individual sports, including sailing (Henriksen et al., 2010a), track and field (Henriksen et al., 2010b), and kayaking (Henriksen et al., 2011), and the team environment of soccer (Larsen, Alfermann, Henriksen, \& Christensen, 2013). Within each of these case studies the overall environment effectiveness was defined by successfully promoting junior level athletes to senior level competition. To our knowledge, there are no explorations of training environments wherein athletes are developed from the grassroots through to Olympic podium performance. These "novel" contexts inculcate athletes' skills and characteristics from one skill level into the next, to reveal how a contextualized career path can be developed from entry to Olympic success.

Found within the open call for this special issue on context-driven sport and exercise psychology practice, Schinke and Stambulova (2016) have encouraged an exchange among sport and exercise practitioners focused on unique cultural and subcultural contexts. We authored this article to provide a cursory description of one high performance artistic sport environment with a history of producing successful Olympians.

\section{Skyriders trampoline training environment}

Henriksen and colleagues (see Henriksen et al., 2010a, 2010b, 2011; Larsen et al., 2013) found that athlete talent development environments are somewhat idiosyncratic. Sport psychologists have previously considered successful sport environments within athlete talent development non-artistic sport environments. Trampoline is an artistic sport (Hanley, 2000) aligned with gymnastics sports including women's and men's artistic gymnastics. Gymnastic sport environments have adopted their own methods for enabling athlete development, including early sport specialization (Stambulova, Stambulov, \& Johnson, 2012) and early extensive practice (Barker-Ruchti \& Schubring, 2016).

Skyriders Trampoline Place in Canada is as an appropriate sport environment to uncover the unique developmental processes of successful Olympic level athletes in trampoline, given that the staff develops athletes from entry to podium. Skyriders has produced many achievements at the international level including four Olympians who have earned all of Canada's seven Olympic trampoline medals. This medal count is the second highest of any country in trampoline Olympic history. Skyriders is also home to a five-time Olympic coach, the current world record holder for the most difficult competition routine, and the only two-time Olympic gold medalist in trampoline Olympic history. 


\section{Exploring skyriders' environment: Participants and method}

Three participants from Skyriders engaged in the study comprised of Canada's Olympic coach, an assistant coach, and one of Skyriders' premiere Olympic athletes. These participants provided perspectives on what makes this context unique; not only in relation to gymnastics sports, but also in terms of how athletes are developed and proceed through career stages and transitions. The Olympic coach was involved with the construction of Skyriders and was able to provide information about how the environment developed over time. The assistant coach has experience both as an elite level athlete and as a coach within the targeted environment. He was able to think retrospectively about his athletic career and his experience developing as a coach. The Olympian provided insight into how Skyriders contributed to her career development and Olympic success.

\section{Situating the authors}

I (the first author) started coaching trampoline at my local club in 2008. During my first competitive season, I inherited a rookie national-level trampolinist. He was a talented athlete and at the end of our first season together he was the National champion for his category. Over his first season he forged a relationship with the Olympic coach and we were invited to Skyriders for training. Ontario's trampoline community holds a general consensus about Skyriders' command of elite trampoline in Canada. As a novice trampoline coach I was drawn to Skyriders because it is home to Canada's trampoline superstars. My previous experiences with Skyriders served as a starting point for this project and provided me a unique opportunity to learn about athlete development in trampoline. The second author is an experienced sport psychology practitioner with Canadian Olympic athletes and an accomplished researcher in elite performance contexts. The third author is an expert in athlete career scholarship with experiences in the holistic ecological research. The fourth author is a Canadian Olympic trampoline coach whose involvement has helped develop the findings in alignment with the idiosyncrasies of Olympic trampoline development. The fifth author is a sport pedagogy scholar.

\section{The guided walks}

The guided walks were a form of mobile conversational interview where the participants provided tours of the Skyriders environment as their unique interviews. Ross, Renold, Holland, \& Hillman (2009) found that during guided walks, participants "...ably communicated their intimate knowledge of their localities" (p. 609). The objective of the guided walks was to have the participants describe their immediate surroundings at Skyriders and how their sport environment contributed to Olympic success. Interviewing participants within Skyriders permitted the use of contextual factors in the training environment (such as equipment and teammates) to serve as cues to prompt knowledge recollection and production (Anderson, 2004). Two of 


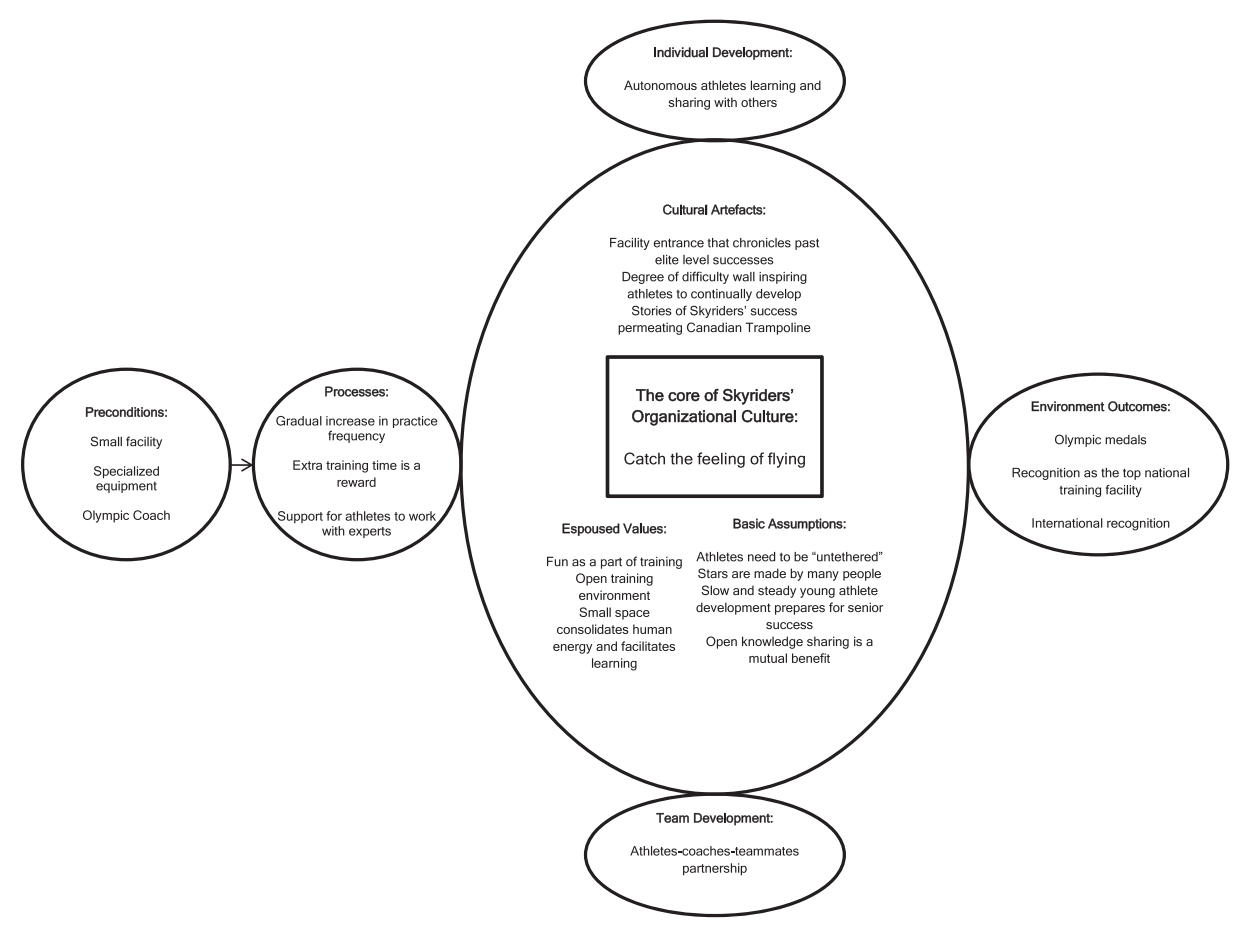

Figure 1. Skyriders' Environmental Success Factors model.

the Skyriders members (athlete and assistant coach) provided the first author with a guided walk that started at the facility entrance and moved inward to the context within its four walls. The Olympic coach's guided walk started from his regular "coaching spot" within the facility and was then focused onto Skyriders' unique structural components. After completing the guided walks, the Olympic coach was engaged in a second conversational interview to further contextualize the information elicited during all of the participants' guided walks in relation to Olympic trampoline development. Additionally, the Olympic coach provided the first author with written documents such as recorded reflections after Olympic Games and Skyriders' website that spanned Skyriders' history. The authors adopted an inductive approach (Braun \& Clarke, 2012; Clarke \& Braun, 2013) and interpreted the data in accordance with the holistic ecological approach to create Skyriders' empirical ESF model (Figure 1) outlining the environment's preconditions, processes, organizational culture, and outcomes.

\section{Skyriders' ESF empirical model: Preconditions}

Skyriders' preconditions are material factors including a small training facility and specialized equipment as well as human factors such as the Olympic coach. At first glance, the Skyriders' facility appeared underwhelming. All participants identified that from their vantages, outsiders assume Canada's Olympic training facility should be big and are surprised when they visit Skyriders. Looking into the Skyriders' gym, the main area of the facility is small and mostly occupied by five trampolines. Four 
of them are arranged end to end and side to side in a two by two fashion, and the fifth trampoline, the "super tramp", is located closest to the observation area. To the left of the trampolines is a strip of floor for warm-ups and some conditioning exercises, and to the right are machines for strength training. There are ropes and bungees hanging from the ceiling that are parts of apparatus. A closer investigation of Skyriders quickly reveals that the floor plan of the training area was designed to maximize the use of a small building footprint. Some of the world's most cutting edge trampoline technology is carefully arranged in Skyriders specifically for elite trampoline development. For example, Skyriders is the only club in Canada to have a super tramp. The super tramp is larger than competition trampolines. The design of the super tramp helps athletes to bounce higher and try skills sooner than they would on regular trampolines.

The Olympic coach was a leader in opening Skyriders and is a unique human factor in the environment. The Olympic coach, with a university degree in physics, operates a trampoline equipment design company that has developed cutting edge trampoline equipment such as the super tramp. His access to high quality equipment has benefited his athletes. For example, the four competition trampoline beds are consistently changed either to test new equipment designs or to imitate equipment that will be used in upcoming major events. The athletes are able to train on a variety of trampolines to prepare for their success.

\section{Skyriders' ESF empirical model: Processes}

Processes are daily activities within STE such as practices that gradually increase in frequency, additional training time provided to athletes as a reward, and support for athletes to work with outside experts.

Skyriders' competitive classes start at age 10. All competitive classes at Skyriders are $1 \mathrm{hr}$ and $45 \mathrm{~min}$ in duration regardless of athletes' competitive level. The frequency of competitive training progresses from two or three times a week for beginner athletes to five times a week for senior athletes. The top few athletes train six times a week and Olympic level athletes have approximately two extra trainings leading up to major events. Although training sessions have scheduled time slots, training time at Skyriders is flexible. Some athletes are known to arrive early to warm up and stay late to cool down whereas others are routinely late and skip training practices. Athletes who demonstrate a strong work ethic are invited to extra training practices. Conversely, if an athlete chooses not to stay until the end of training, they are allowed to leave. However, a lack of commitment on the part of an athlete will be reciprocated by a lack of involvement on the part of the coach. Skyriders' athletes who demonstrate a strong work ethic are rewarded with coach engagement and extra training time.

STE focuses on trampoline development. Athletes who are interested in working with other experts, such as sports psychologists or strength and conditioning coaches, are able to seek out external resources. Although the athletes are responsible for making their own arrangements to work with other professionals, the Olympic 
coach maintains open communication with all parties involved in Skyriders' athletes' development.

\section{Skyriders' ESF empirical model: Organizational culture and outcomes}

At the core, Skyriders' culture encourages athletes to "catch the feeling of flying". Skyriders' organizational culture, including the cultural artifacts, espoused values and basic assumptions, are aligned to thrill young athletes with the freedom of flying early in their careers and support them as they rise to the challenge of Olympic trampoline.

\section{Cultural artifacts}

Cultural artifacts are stories from the STE that pertain to previous successful athletes, the degree of difficulty wall, and trampoline success stories that permeate Canadian trampoline. Skyriders' past successes are documented on the walls of the facility entrance via photos and newspaper stories of Olympic medalists. Although many clubs in Canada have a "wall of fame" where pictures of provincial and national athletes are documented, Skyriders uniquely documents repetitive Olympic level successes. The assistant coach highlighted that past achievements at Skyriders are also recorded on the degree of difficulty wall in the training area. The degree of difficulty wall has the names and difficulty levels of every national level routine performed at Skyriders. The wall helps to keep current athletes motivated and focused on their development as they try to raise their name higher on the wall by performing more difficult routines. The stories of successful elite performances remind current athletes that elite level success is nearby.

Skyriders' success stories do not only focus on the Olympic athletes. Over time, the Olympic coach has become synonymous with Canadian trampoline achievements within the trampoline community. Knowledgeable coaches are a key component to athlete development (Bloom, 1985; Côté et al., 1995; Giginov \& Sandanski, 2004). The Olympic coach's prestige within Canada and abroad has generated athlete "buy in" at Skyriders.

\section{Espoused values}

STE's espoused values are the social principles, goals, and standards that are presented to the broader trampoline community. Skyriders' espoused values include "fun" during training sessions, an open training environment, and "human energy" manifested from a small training space.

Skyriders promotes a fun and open training environment to the trampoline community. The "fun" in Skyriders' training environment is evident in social media posts and advertising put out by the facility. Posts on social media depict elite athletes from Skyriders playing games and challenging themselves with unconventional acrobatic skills on trampoline equipment. The Olympic coach credited a past athlete, who 
always wanted to incorporate games into training, with infusing fun into the Skyriders' culture. The games and enjoyment embedded in the training environment echo the findings from Storm, Henriksen, and Christensen (2012) that play can be an important characteristic in the specialization pathways of elite athletes. Fun training at Skyriders has saturated the local trampoline community to the point that outside athletes do not always appreciate how hard the elite athletes train on a routine basis. The Olympian noted that visiting athletes often underestimate Skyriders' elite athletes' work ethic given that training is portrayed to the wider trampoline community as games.

Skyriders has also projected a welcoming environment that compliments their fun atmosphere and invites other Canadian and international coaches and athletes to train at the facility. Visitors who participate actively in training sessions benefit the Skyriders environment because, as the Olympic coach noted, Skyriders' athletes train harder to impress their guests. Conversely, the assistant coach expressed that visiting coaches who passively observe training sessions detract from the training environment because they take attention away from the athletes without reciprocally contributing to the training session.

Although visitors to Skyriders expect a larger training facility, the participants noted that Skyriders' small facility space has contributed to what they identified as "human energy" during training. The participants felt that the small space provides a venue conducive to collaboration and a larger facility would detract from athlete development. Learning can be contagious, and when one athlete learns something new at Skyriders their teammates notice and the facility gets excited to progress together.

\section{Basic assumptions}

The participants helped to identify four underlying basic assumptions that are underlying reasons for actions in the STE: (1) athletes need to be "untethered", (2) stars are made by many people (i.e., coaches, teammates), (3) slow and steady athlete development, and (4) open knowledge sharing is a mutual benefit.

First, elite trampolinists require autonomy and independence. During the technical preparation for high level trampoline skills, athletes are often tethered to a rope harnesses. A rope harness tethers an athlete to the ceiling by a system of pulleys to protect the athlete from falling. Athletes need to be adequately prepared in order to complete a new skill untethered. If an error occurs during a skill, trampolinists need to know how to make quick adjustments independently to land safely. Athletes at Skyriders learn how to make decisions autonomously because the Skyriders coaches give athletes control over their training trajectory. Coaches at Skyriders ask athletes questions in order to facilitate their development rather than tethering the athlete to the coaches input and influence. Skyriders coaches, then, prepare athletes "to untether themselves and fly".

Second, STE promotes that stars are made by many people. Skyriders' teammates influence each other in two ways: the senior athletes are used as models for the junior 
athletes and vice versa. The senior athletes model appropriate training habits and demonstrate skills for the junior athletes to aspire to. The junior athletes reciprocate by continually motivating the senior athletes. Seeing young athletes develop in the sport focuses the senior athletes on continual development to stay amongst the top ranked in the world. Modeling is influential in the development of elite level athletes (Durand-Bush \& Salmela, 2002; Martindale et al., 2005) and is critical in other sport environments (Henriksen et al., 2010a, 2011). Uniquely, the Olympic coach identified that throughout each Olympian's career he worked with, there was a specific teammate that helped to push the athlete to the next level. Hence, there are stars and "star makers". The Olympian remembered a teammate who was not as naturally talented as she, but more stubborn and able to learn. The learning pace and dedication of the star maker, including her resilience, helped to push the Olympian to her success.

Third, the Olympic coach believes that slow and steady early athlete development prepares athletes for future senior level success. STE is organized to allow athletes control over their level of training intensity. The Olympic coach feels that athletes are able to make this choice after the age of 15 without being influenced by their parents or their coaches. Members of Skyriders are able to choose their level of intensity without reprise from the coaching staff. The Olympic coach noted that this approach keeps his athletes skill development five years behind the rest of the world. The athletes make up for their "delayed" training time because they are physically and mentally healthy and can consequently train harder at a later stage. The participants noted that this approach encourages Skyriders' athletes to pursue interests outside of trampoline, including educational goals and other sport activities such as snowboarding. The Skyriders' membership has embraced the Olympic coach's slow and steady approach to athlete development and this philosophy has permeated other coaches' tactics.

Fourth, Skyriders' open exchange of information has perceived mutual benefits for the Skyriders' members and their national and international competitors. The Olympic coach, similar to findings in sailing (Henriksen et al., 2010a) and track and field (Henriksen et al., 2010b) environments, does not believe in harboring training secrets. He believes that if he shares his knowledge with competitors, the Skyriders' athletes and coaches will have to improve in order to stay competitive. Also, inviting outside athletes to train at Skyriders provides the Skyriders' athletes and staff with the opportunity to learn from other trampoline clubs. The Olympian shared that she has had the opportunity to train at other trampoline clubs internationally because of Skyriders' hospitality. Other successful trampoline environments are semi-closed where the training facilities have selective access (Yang et al. 2015). Skyriders has the philosophy that if their competitors get better, they get better.

\section{Outcomes}

STE's unique preconditions and processes are worked through the organizational culture to facilitate individual athlete development, team development, and the 
overall environmental effectiveness. Individual athlete development within STE manifests as autonomous athletes who learn and share with others. STE develops autonomy by encouraging athletes to problem solve and make decisions during training. Team development can be seen in the partnerships forged between athletes, coaches, and teammates. Teammate partnerships are encouraged through modeling and the interactions 'imposed' on athletes in the small training space. Furthermore, STE promotes athletes to have a voice in their training trajectory and supports athletes to work as partners with their coach. Successful elite coach-athlete teams work as partnerships (Orlick \& Partington, 1988; Schinke et al., 2008; Yang et al., 2015) and STE supports the athlete's role in the coach-athlete relationship. Lastly, the overall environmental effectiveness is expressed through the multiple Olympic medals won by Skyriders athletes, Skyriders recognition as Canada's national training facility and the international recognition for Canada's ability to produce top trampolinists.

\section{Conclusions}

The Skyriders' ESF empirical model augments our understanding of a unique sport environment that facilitates athlete transitions from grass roots to the Olympic podium. Whereas researchers have previously highlighted sport environments that support athletes during a single transition, the Skyriders' environment supports athletes in navigating an entire elite sports career. Going forward, practitioners can further consider how STE has supported Olympic athletes through team interconnectedness, the influence of "star makers", and promoting high-intensity training later than what is currently promoted in other artistic sport contexts.

First, practitioners need to consider how the design of a sport environment can promote teammate interactions. Previous case studies (Henriksen et al., 2010a) have identified that strong teammate relationships help support elite athletes. STE has maximized athlete training outcomes through "human energy" created by the group's interconnectedness. Focusing training in a concentrated area encourages teammate interactions. Practitioners in large and small sport environments alike should consider if training sessions are structured to permit adequate opportunities for athletes to observe, support, and interact with each other. Training practices that facilitate interconnectedness amongst teammates will support the development of every athlete. Second, Skyriders highlights how teammates can inculcate each other with appropriate skills for elite level success. Practitioners might further explore the influence of teammates as "star makers". Although "star makers" did not experience Olympic success, they were central to the development of each Olympian. Sport psychologists could help maximize athlete development by working with teams to evaluate the strengths and weaknesses of each athlete and arranging athletes in complimentary pairings (i.e., partnering athletes together who have opposing strengths and weaknesses). Establishing complimentary pairings could help athletes learn from each other and guide each other to a higher level. We ponder whether or not "star makers" may be identifiable during the athlete development process. However, care 
needs to be taken that practitioners are not labelling athletes as "star makers" from the beginning. Olympic level performers are not readily identifiable at the beginning of their sport career (Gullich \& Emrich, 2006; Henriksen et al., 2010b; Henriksen et al., 2011). Therefore, attempting to identify "star makers" may place inappropriate limitations on athletes who might be late developers or unusually resilient. Furthermore, if a coach typecasts an athlete as a "star maker", these athletes may never be given the support they need to reach their full potential.

Third, Skyriders provides cause for practitioners to reconsider current best practices promoted in other artistic sport contexts. Presently, artistic sports adopt a developmental timeline that encourages early intense practice (Barker-Ruchti \& Schubring, 2016; Stambulova et al., 2012). Comparatively, Skyriders promotes high-intensity training after the age of 15. This time frame corresponds with the recommendations for other non-artistic youth sport contexts (see Bloom 1985; Côté, Baker, \& Abernathy, 2003; Martindale et al., 2005). Sports psychologists that encourage artistic sport environments to embrace Skyriders' slow and steady approach may help protect young athletes from the negative outcomes associated with early intense practice such as burn out and manipulation from adults (Malina, 2010), while still nurturing their Olympic potential. Protecting young athletes early in their sport careers increases the likelihood that they will continue within a sport long enough to develop into elite competitors, potentially all the way to the podium.

The scope of this article was to take a preliminary step to inform practitioners about unique contextual factors present in an athlete talent development environment that supports athletes' development from grass roots to podium. Skyriders provides insight into how environmental factors can interact to create an organizational culture conducive to Olympic-level accomplishments. Practitioners open to learning from Skyriders will hopefully help future Olympians "catch the feeling of flying" in their own athletic ventures.

\section{ORCID}

Natalia B. Stambulova ๑ http://orcid.org/0000-0001-6198-0784

\section{References}

Anderson, J. (2004). Talking whilst walking: A geographical archaeology of knowledge. Area, 36(3), 254-261. doi:10.1111/j.0004-0894.2004.00222.x

Barker-Ruchti, N., \& Schubring, A. (2016). Moving into and out of high-performance sport: The cultural learning of an artistic gymnast. Physical Education and Sport Pedagogy, 21(1), 69-80. doi:10.1080/17408989.2014.990371

Bloom, B. S. (1985). Developing talent in young people. New York, NY: Ballantine Books.

Braun, V., \& Clarke, V. (2012). Thematic Analysis. In Cooper, H. (Ed.), APA handbook of research methods in psychology (Vol. 2: Research Designs). Washington, DC: American Psychological Association. 
Bronfenbrenner, U. (1994). Ecological models of human development. In T. Husén \& T. N. Postlethwaite (Eds.), The International Encyclopaedia of Education (vol. 3, 2nd ed). Oxford, UK: Elsevier.

Brown, B. (1985). Factors influencing the process of withdrawal by female athletes from the role of competitive age group swimmer. Sociology of Sport Journal, 2(2), 111-129. doi:10.1123/.ssj.2.2.111

Bruner, M. W., Munroe-Chandler, K. J., \& Spink, K.S. (2008). Entry into elite sport: A preliminary investigation into the transition experiences of rookie athletes. Journal of Applied Sport Psychology, 20(2), 236-252. doi:10.1080/10413200701867745

Clarke, V., \& Braun, V. (2013). Teaching thematic analysis: Overcoming challenges and developing strategies for effective learning. The Psychologist, 26(2), 120-123.

Côté, J., Baker, J., \& Abernathy, B. (2003). From play to practice: A developmental framework for the acquisition of expertise in team sport. In J. Starkes \& K. A. Ericsson (Eds.), Expert performance in sports: Advances in research on sport expertise (pp. 89-113). Champaign, IL: Human Kinetics.

Côté, J., \& Salmela, J. (1996). The organizational tasks of high-performance gymnastics coaches. The Sport Psychologist, 10(3), 247-260. doi:10.1123/tsp.10.3.247

Côté, J., Salmela, J., Trudel, P., Baria, A., \& Russell, S. (1995). The coaching model: A Grounded assessment of expert gymnastic coaches' knowledge. Journal of Sport and Exercise Psychology, 17(1), 1-17. doi:10.1123/jsep.17.1.1

Durand-Bush, N., \& Salmela, J. (2002). Development and maintenance of expert performance: Perceptions of world champions. Journal of Applied Sport Psychology, 14(3), 154-17. doi:10.1080/10413200290103473ag

Girginov, V., \& Sandanski, I. (2004). From participants to competitors: The transformation of British gymnastics and the role of the Eastern European model of sport. The International Journal of History of Sport, 21(5), 815-832. doi:10.1080/09523360420002079

Gullich, A., \& Emrich, E. (2006). Evaluation of the support of young athletes in the elite sports system. European Journal for Sport and Society, 3(2), 85-108.

Hanley, E. A. (2000). A perennial dilemma: Artistic sports in the Olympic Games. Journal of Olympic History, 8(2), 39-46.

Henriksen, K., Stambulova, N., \& Roessler, K. K. (2010a). Holistic approach to athlete talent development environments: A successful sailing milieu. Psychology of Sport and Exercise, 11(3), 212-222. doi:10.1016/j.psychsport.2009.10.005

Henriksen, K., Stambulova, N., \& Roessler, K. K. (2010b). Successful talent development in track and field: considering the role of environment. Scandinavian Journal of Medicine \& Science in Sports, 20(s2), 122-132. doi:10.1111/j.1600-0838.2010.01187.x

Henriksen, K., Stambulova, N., \& Roessler, K. K. (2011). Riding the wave of an expert: A successful talent development environment in kayaking. The Sport Psychologist, 25(3), 341-362. doi:10.1123/tsp.25.3.341

Larsen, C., Alfermann, D., Henriksen, K., \& Christensen, M. K. (2013). Successful talent development in soccer: The characteristics of the environment. Sport, Exercise and Performance Psychology, 2(3), 190-206. doi:10.1037/a0031958

Malina, R. M. (2010). Early sport specialization: Roots, effectiveness, risks. Current Sports Medicine Reports, 9(6), 364-371. doi:10.1249/JSR.0b013e3181fe3166

Martindale, R. J., Collins, D., \& Daubney, J. (2005). Talent development: A guide for practice and research within sport. Quest, 57(4), 353-375. doi:10.1080/00336297.2005.10491862

Morgan, T. K., \& Giacobbi Jr., P. R. (2006). Toward two grounded theories of talent development and social support process highly successful collegiate athletes. The Sport Psychologist, 20(3), 295-313. doi:10.1123/tsp.20.3.295 
Morris, R., Tod, D., \& Oliver, E. (2016). An investigation into stakeholders' perceptions of the youth-to-senior transition in professional soccer in the United Kingdom. Journal of Applied Sport Psychology, 28(4), 375-391. doi:10.1080/10413200.2016.1162222

Orlick, T., \& Partington, J. (1988). Mental links to excellence. The Sport Psychologist, 2(2), 105130. doi:10.1123/tsp.2.2.105

Ross, N., Renold, E., Holland, S., \& Hillman, A. (2009). Moving stories: using mobile methods to explore the everyday lives of young people in public care. Qualitative Research, 9(5), 605-623. doi:10.1177/1468794109343629

Schein, E. (1992). Organizational culture and leadership. San Francisco, CA: Jossey-Bass.

Schinke, R. J., Battochio, R. C., Dubuc, N. G., Swords, S., Apolloni, G., \& Tenenbaum, G. (2008). Understanding the adaptation strategies of Canadian Olympic athletes using archival data. Journal of Clinical Sports Psychology, 2(4), 337-356. doi:10.1123/jcsp.2.4.337

Schinke, R. J., \& Stambulova, N. B. (2016). Context-driven sport and exercise psychology practice. Journal of Sport Psychology in Action, 7(1), 56-57. doi:10.1080/21520704.2016.1143759

Schinke, R. J., Stambulova, N. B., Trepanier, D., \& Oghene, O. (2015). Psychological support for the Canadian Olympic boxing team in meta-transitions through the national team program. International Journal of Sport and Exercise Psychology, 13(1), 74-89. doi:10.1080/1612197X.2014.959982

Stambulova, N. (1994). Developmental sport career investigations in Russia: A post-perestroika analysis. The Sport Psychologist, 8(3), 221-237. doi:10.1123/tsp.8.3.221

Stambulova, N., Stambulov, A., \& Johnson, U. (2012). "Believe in Yourself, Channel Energy, and Play Your Trumps": Olympic preparation in complex coordination sports. Psychology of Sport and Exercise, 13(5), 679-686. doi:10.1016/j.psychsport.2012.04.009

Storm, L. K., Henriksen, K., \& Christensen, M. K. (2012). Specialization pathways among elite Danish athletes: A look at the developmental model of sport participation from a cultural perspective. International Journal of Sport Psychology, 43(3), 199-222.

Wylleman, P., Reints, A., \& De Knop, P. (2013). A developmental and holistic perspective on athletic career development. In P. Sotiaradou \& V. De Bosscher (Eds.), Managing high performance sport (pp. 159-182). New York, NY: Routledge.

Yang, G., Schinke, R. J., Dong, D., Lu, C., Si, G., \& Oghene, P. (2016). Working with Chinese Olympic athletes in their national sport system: From the conceptual to a proposed research - practice dialectic. International Journal of Sport and Exercise Psychology. Advance online publication. doi:10.1080/1612197X.2016.1164227 